
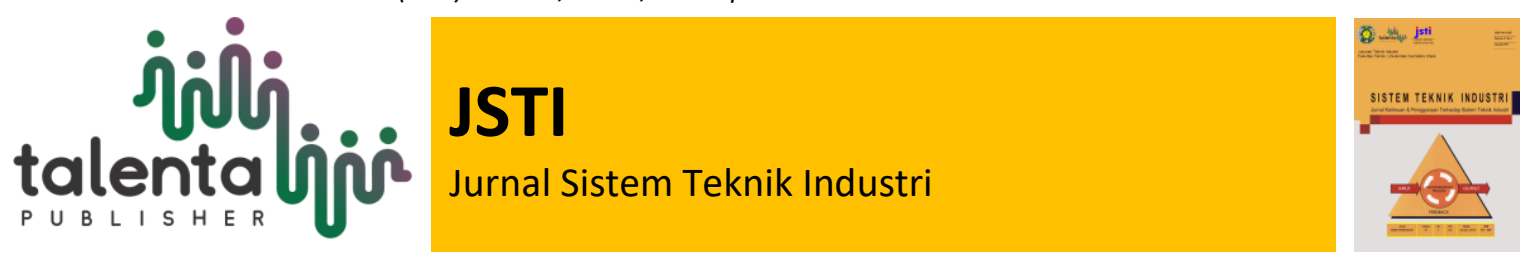

\title{
Optimalisasi Waktu Produksi, Jumlah Produksi, Dan Jalur Distribusi Pada Oulet Lazatto di Karawang
}

\author{
Cici Lestari', Rianita Puspa Sari ${ }^{2}$
}

${ }^{1,2}$ Program Studi Teknik Industri, Fakultas Teknik, Universitas Singaperbangsa Karawang, Karawang

\begin{abstract}
The development of the food and beverage business is still recorded as a number of high developments in this world, the types of food and beverage in various forms have increased because food is one of the basic needs that must be met. Lazatto is a food industry that is engaged in various fields of fast food restaurants by producing processed chicken. The problems that occur at Lazatto are the inability to maximize the amount of chicken production, optimize the production time for employees, and the distribution channel to determine the shortest route to utilize raw materials. The purpose of this research is to analyze the optimization of working time using the Hungarian method or assignment, the amount of production using the Branch and Bound method, and the distribution line using the Minimum Spanning Tree method. The results showed that the optimal working time is 83 minutes or 1 hour 23 minutes / one time production, the amount of production in one production is 23 pieces with a combination of 5 pieces of geprek chicken, 4 pieces of sadas chicken, and 14 pieces of fried chicken, with The optimal total distance for the distribution of raw materials is $137.6 \mathrm{~km}$.
\end{abstract}

Keyword: Branch and Bound, Hungarian, Minimum Spanning Tree

\begin{abstract}
Abstrak. Perkembangan bisnis makanan dan minuman masih tercatat sebagai perkembangan yang tinggi di dunia ini, berbagai jenis makanan dan minuman dengan berbagai bentuk telah melonjak karena makanan merupakan salah satu kebutuhan mendasar yang harus dipenuhi. Lazatto merupakan industri makanan yang bergerak di bidang restoran cepat saji dengan memproduksi berbagai olahan ayam. Permasalahan yang terjadi di Lazatto adalah ketidakmampuan untuk memaksimalkan jumlah produksi ayam, pengoptimalisasian waktu produksi karyawan, dan jalur distribusi untuk menentukan rute terpendek guna mendistribusikan bahan baku. Tujuan dari penelitan ini adalah untuk menganalisa optimalisasi waktu kerja dengan menggunakan metode Hungarian atau assignment, jumlah produksi dengan menggunakan metode Branch and Bound, dan jalur distribusi dengan menggunakan metode Minimum Spanning Tree. Hasil penelitian menunjukkan bahwa waktu kerja yang paling optimum adalah 83 menit atau 1 jam 23 menit/satu kali produksi, jumlah produksi dalam satu kali produksi sebanyak 23 potong dengan kombinasi 5 potong ayam geprek, 4 potong ayam sadas, dan 14 potong ayam goreng, dengan total jarak optimum jalur distribusi bahan baku yaitu 137,6 km.
\end{abstract}

Kata Kunci: Branch and Bound, Hungarian, Minimum Spanning Tree

Received 20 November 2020 | Revised 15 December 2020 | Accepted 23 January 2021

*Corresponding author at: Universitas Singaperbangsa Karawang, 41361, Indonesia

E-mail address: rianita.puspasari@ft.unsika.ac.id 


\section{Pendahuluan}

Industri makanan dan minuman saat ini masih tecatat sebagai industri yang berkembang pesat di berbagai belahan dunia [1]. Banyak gerai makanan dan minuman menawarkan produknya dalam struktur yang berbeda, mulai dari makanan pokok hingga makanan yang mewah. Karena pangan merupakan salah satu kebutuhan esensial manusia yang harus dipenuhi. Penjelasan logis di balik bisnis yang berkembang pesat adalah dengan alasan bahwa bisnis makanan saat ini dapat menghasilkan keuntungan yang sangat besar. Perkembangan industri makanan dan minuman dapat dilihat pada Gambar 1 yang menggambarkan pesatnya kemajuan di industri jasa makanan [2] Pertumbuhan industri makanan dan minuman di iringi dengan banyaknya juga restoran cepat saji seperti halnya Lazatto yang merupakan restoran cepat saji secara franchise yang menyajikan makanan ala resto terkemuka dengan harga yang murah sehingga mudah di temui pada beberapa lokasi khususnya area kampus.

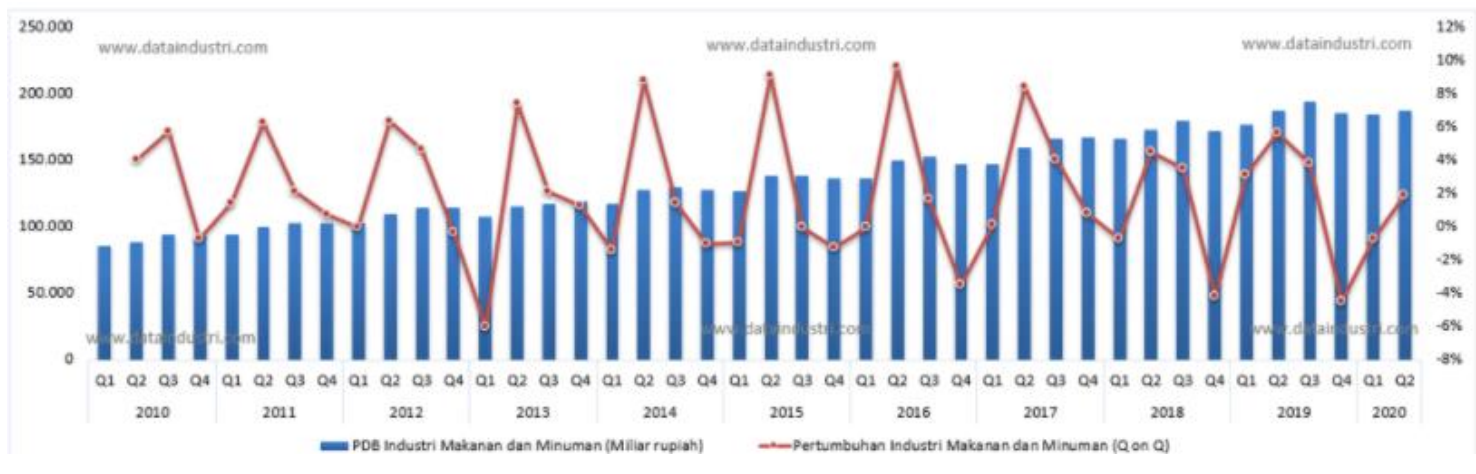

Gambar 1 Pertumbuhan Industri Makanan dan Minuman

Kasus yang berkaitan dengan alokasi optimal yang bersumber dari personalia memiliki tingkat efisiensi pekerjaan yang berbeda, hal ini menjadi kasus yang kerap dihadapi dalam dunia usaha dan industri khususnya pada restoran cepat saji. Masalah penugasan merupakan persoalan yang berkaitan dengan aturan pada tiap individu ketika melaksanakan tugas, sehingga dalam pelaksanaan tugasnya dapat meminimalkan biaya atau waktu yang diperlukan [3]. Begitu pula masalah yang dihadapi oleh Lazatto dalam masalah penugasan adalah menentukan waktu produksi yang minimal. Berdasarkan observasi lapangan serta studi literatur dapat diketahui adanya permasalahan dalam meminimasi waktu produksi dengan metode Hungarian karena menurut S. Bariasti \& A. Lestari [4] metode ini dapat dipakai. Hal ini dibuktikan oleh penelitian Erlinda Rahmawati yang telah membahas tentang optimalisasi masalah penugasan dengan metode Hungarian, penelitian tersebut menunjukkan bahwa metode Hungarian lebih optimal dibandingkan penugasan yang dilakukan perusahaan dalam penempatan karyawan [5].

Selain itu, terdapat masalah lain mengenai optimalisasi jumlah produksi. Menentukan jumlah produksi barang yang optimal merupakan hal yang diinginkan semua perusahaan untuk meningkatkan pendapatan perusahaan [6]. Hal ini berhubungan dengan penjadwalan. Penjadwalan merupakan pembagian sumber daya dari waktu ke waktu agar setiap pekerjaan dapat tersturuk pelaksanaan dan penyelesaiannya. Penentuan distribusi sumber daya perusahaan ditunjukkan untuk memenuhi target penerapan sumber daya secara efektif dan efisien, agar 
menghasilkan output ukuran hasil yang sempurna, kualitas yang tepat, dan waktu yang ideal. [7] [8] [9]. Berdasarkan observasi lapangan serta studi literatur dapat diketahui adanya permasalahan mengenai penjadwalan produksi yang dapat diselesaikan dengan metode Branch and Bound. Menurut [10] metode Branch and Bound dapat dipakai untuk penjadwalan produksi yang membuktikan optimalisasi produksi serta hasil penjualan [11]. Mengacu pada penelitian ini [5]; [11] penelitian ini berkontribusi dalam memadukan dua metode untuk optimalisasi waktu dan jumlah produksi serta biaya yang dihitung secara simultan.

Permasalahan lainnya yaitu menentukan jalur distribusi untuk memilih rute terdekat untuk mendistribusikan bahan baku. Penentuan jalur atau rute menjadi salah satu aktivitas penting dalam proses pendistribusian barang. Keterlambatan dan ketidaktetapan waktu pengiriman barang sangat berpengaruh dalam proses pemasaran ketika dihubungkan dengan masalah jarak tempuh yang diperlukan [12], total jarak tempuh juga mempengaruhi biaya yang dikeluarkan, semakin jauh jarak semakin mahal biaya yang dikeluarkan [13] [14] [15] [16] . Berdasarkan observasi lapangan serta studi literatur dapat diketahui adanya permasalahan mengenai jalur distribusi untuk menentukan rute terpendek yang dapat diselesaikan dengan menggunakan metode Minimum Spanning Tree (pohon rentang minimum), karena menurut A, Rahmawati \& Mulyono [12], metode ini dapat dipakai. Hal ini dibuktikan oleh beberapa peneliti sebelumnya yang menyatakan bahwa dalam menangani kasus minimasi biaya dan pengoptimalan jarak tempuh dapat menggunakan metode Minimum Spanning Tree. Minimum Spanning Tree dapat diaplikasikan di bidang transportasi, energi dan jaringan komunikasi. [17] [18]. Berbeda halnya dalam penelitian ini objek penelitian dengan opimalisasi untuk menemukan rute terdekat untuk mendistribusikan bahan baku kesetiap cabang Lazatto di Karawang.

Maka dari itu tujuan dari penelitan ini yaitu untuk menganalisa optimalisasi waktu kerja dengan menggunakan metode Hungarian atau assignment, optimalisasi jumlah produksi dengan menggunakan metode Branch and Bound, dan jalur distribusi untuk menemukan rute terdekat dengan menggunakan metode Minimum Spanning Tree pada Lazatto Cabang UNSIKA di Karawang.

\section{Metode Penelitian}

Penelitian ini termasuk penelitian kuantitatif karena menggunakan data berupa angka-angka dan analisis menggunakan statistik sebagai alat untuk mengevaluasi data yang perlu diketahui. [19] Penelitian dilakukan di Oulet Lazatto yang berada di Teluk Jambe Timur. Oulet Lazatto ini berlokasi di Jl. H.S. Ronggo Waluyo, Puseurjaya, Kec. Telukjambe Tim., Kabupaten Karawang, Jawa Barat, 41361.

Tahapan yang mendasari dalam studi Riset Operasional adalah mengenali isu-isu yang digunakan sebagai bahan penelitian, membangun model untuk mencerminkan kasus-kasus yang akan disurvei, menyelesaikan model untuk menemukan model yang valid, validasi model untuk menguji model dan hasil pemecahan dari penggunaan model, mengaktualisasi hasil akhirnya [20]. 
Data primer dikumpulkan langsung dari hasil wawancara langsung pada pimpinan oulet lazatto cabang UNSIKA di Karawang dan pegawai perusahaan. Hasil Wawancara berupa data parameter yang dibutuhkan untuk penelitan mengenai proses produksi, distribusi perusahaan, jadwal penugasan atau pembagian kerja setiap pegawai. Pengolahan data dilakukan dengan menggunakan metode Branch and Bound, Hungarian, dan Minimum Spanning Tree.

\subsection{Branch and Bound}

Metode Branch and Bound adalah metode untuk mendapatkan solusi terbaik terhadap kasus yang sedang ditinjau. Untuk mendapatkan hasil agar bisa dianalisa harus melakukan pengolahan data terlebih dahulu [21].

Tahapan Penyelesaian metode Branch and Bound [22]:

1. Tahap awal dalam menyelesaikan kasus Integer Linear Programming yaitu anggap kasus Integer Linear Programming seperti kasus Llinear Programming, dalam Menentukan solusinya menggunakan metode simpleks.

2. Jika mendapatkan hasil optimal dengan semua variabelnya bilangan bulat, maka solusi Linear Programming tersebut menjadi solusi optimal Integer Linear Programming. Sedangkan apabila sebagian variabelnya bukan bilangan bulat, pilih salah satu variable tersebut untuk melakukan percabangan sehingga diperoleh submasalah Integer Linear Programming.

3. Kembali ke langkah pertama untuk menyelesaikan submasalah tersebut, tentukan solusi submasalah yang memiliki nilai tertinggi Upper Bound (Bounding).

4. Apabila solusi tersebut belum memenuhi syarat integer, maka lakukan percabangan kembali dan selesaikan submasalah tersebut seperti pada langkah tiga, sampai mendapatkan bilangan bulat.

\subsection{Hungarian}

Metode Hungarian adalah metodologi dengan mengubah antar baris dan kolom pada matriks efektifitas hingga muncul satu komponen nol disetiap baris atau komponen yang akan dipilih sebagai penugasan [23].

Tahapan Penyelesaian metode Hungarian [23] adalah:

1. Mengkonversikan tabel tugas ke dalam matriks efektifitas.

2. Pilih bobot terkecil pada setiap baris, lalu lakukan pengurangan setiap baris dengan bobot terkecil disetiap baris.

3. Pilih bobot terkecil pada setiap kolom, lalu lakukan pengurangan setiap kolom dengan bobot terkecil disetiap kolom.

4. Tarik garis dengan jumlah minimum untuk menutupi semua angka nol dari matriks atau tabel, garis vertical untuk scan baris, dan garis horizontal untuk scan kolom.

5. Jika jumlah garis sama dengan jumlah baris dari matriks, lanjutkan ke tahap 7, jika tidak lanjutkan ke tahap 6. 
6. Pilih nilai minimum dari nilai entri yang belum tercoret, lakukan penjumlahan entri yang berada di perpotongan baris dengan nilai minimum yang sudah dipilih dan lakuka pengurangan pada entri yang belum tercoret dengan nilai minimum tersebut, lalu kembali ke langkah 4 .

7. Solusi optimal adalah semua entri yang ditandai dengan kotak atau bilangan 0 .

\subsection{Minimum Spanning Tree}

Penyelesaian kasus Analisa jaringan dapat menggunakan metode Minimum Spanning Tree dengan cara menghubungkan setiap simpul atau node yang terdekat guna menghasilkan total rute yang minimum [16].

Tahap umum dalam penyelesaian kasus Minimum Spanning Tree adalah dengan menghubungkan setiap simpul yang memiliki nilai terkecil ke node terdekat, langkah tersebut dilakukan secara berulang sampai membentuk graf dan tanpa adanya looping [24].

\section{Hasil dan Pembahasan}

Penelitian ini menggunakan data primer yang dikumpulkan dari hasil wawancara langsung pada pimpinan oulet lazatto cabang UNSIKA di Karawang dan pegawai perusahaan. Pengumpulan data primer berupa parameter penelitian yang dibutuhkan sehingga didapatkan informasi mengenai data proses produksi dan distribusi perusahaan. Sedangkan dari pegawai mendapatkan informasi data mengenai penugasan atau pembagian kerja setiap pegawai. Setelah pengumpulan data didapatkan, maka dilajutkan pengolahan data dengan menggunakan metode Branch and Bound, Hungarian, dan Minimum Spanning Tree. Adapun hasil dan pembahasan setiap metode terinci pada sub-bab.

\subsection{Hasil Perhitungan Metode Branch and Bound}

Asumsikan:

$\mathrm{X} 1$ = Jumlah ayam geprek yang diproduksi/satu kali penggorengan

$\mathrm{X} 2$ = Jumlah ayam sadas yang diproduksi/satu kali penggorengan

$\mathrm{X} 3$ = Jumlah ayam goreng yang diproduksi/satu kali penggorengan

Fungsi tujuan:

Memaksimumkan

$\mathrm{Z}=16.000 \mathrm{X} 1+18.000 \mathrm{X} 2+14.000 \mathrm{X} 3+\mathrm{S} 1+\mathrm{S} 2+\mathrm{S} 3+\mathrm{S} 4+\mathrm{S} 5+\mathrm{S} 6+\mathrm{S} 7$

Kendala:

$$
\begin{aligned}
& 123 x_{1}+117 x_{2}+110 x_{3}+\mathrm{s} 1 \leq 2750 \\
& 25 x_{1}+30 x_{2}+25 x_{3}+\mathrm{s} 2 \leq 1550 \\
& 77 x_{2}+\mathrm{s} 3 \leq 350 \\
& 20 x_{1}+\mathrm{s} 4 \leq 125 \\
& 10 x_{1}+7 x_{2}+5 x_{3}+\mathrm{s} 5 \leq 225
\end{aligned}
$$


$523 x_{1}+517 x_{2}+450 x_{3}+\mathrm{s} 6 \leq 27500$

$30 x_{1}+25 x_{2}+20 x_{3} \leq 720$

Pada Tabel 1 dapat terlihat parameter data berupa persediaan bahan baku dan waktu produksi yang terdapat tiga variabel keputusan yang menunjukkan jumlah ayam geprek, ayam sadas, dan ayam sadas yang diproduksi setiap hari, kemudian data di olah dengan metode simpleks yang ditambahkan variabel slack.

Tahap awal penyelesaian dengan metode simpleks akan dioleh dengan software LINGO dengan cara menginput nilai fungsi tujuan dan fungsi kendala, hasil penyelesaian memperoleh nilai X1 = $6,25, \mathrm{X} 2=4,545455, \mathrm{X} 3=13,17665$. Karena pegawai lazatto tidak dapat memproduksi ayam dalam bentuk pecahan, maka penyelesaian selanjutnya menggunakan pemrograman bilangan bulat Integer Linear Programming dengan metode Branch and Bound untuk menciptakan nilai bulat optimal.

Tahap yang mendasari dalam menyelesaikan solusi integer dengan menggunakan teknik branch and bound adalah menentukan batas awal dan batas bawah solusi optimal dari metode simpleks yaitu, $\mathrm{X} 1=6,25, \mathrm{X} 2=4,545455, \mathrm{X} 3=13,17665$, dijadikan batas awal memperoleh nilai $\mathrm{z}=$ Rp.372,541.3.-. Pembulatan kebawah sebagai batas bawah yakni : $X 1=6, X 2=4, \quad X 3=13$ memperoleh nilai $\mathrm{z}=\mathrm{Rp} .356 .000$.-

Tahap selanjutnya tentukan solusi submasalah yang memiliki nilai tertinggi (Upper Bound), apabila submasalah yang menjadi Upper Bound belum mendapatkan hasil bilangan bulat, maka proses percabangan terus berlanjut sampai mendapatkan hasil bilangan bulat. Pada penelitian ini hasil optimal percabangan dengan menggunakan metode Branch and Bound di dapatkan sebanyak 2 kali iterasi menggunakan software LINGO. Dapat dilihat pada Gambar 2.

Tabel 1 Data Produksi Lazatto di Karawang Cabang UNSIKA

\begin{tabular}{|c|c|c|c|c|c|}
\hline \multirow[b]{2}{*}{ Bahan } & \multicolumn{3}{|c|}{ Jenis Ayam } & \multirow[t]{2}{*}{$\begin{array}{l}\text { Persediaan } \\
\text { Maksimal }\end{array}$} & \multirow[t]{2}{*}{ Satuan } \\
\hline & $\begin{array}{c}\text { Ayam } \\
\text { Geprek }\end{array}$ & $\begin{array}{l}\text { Ayam } \\
\text { Sadas }\end{array}$ & $\begin{array}{c}\text { Ayam } \\
\text { Goreng }\end{array}$ & & \\
\hline Ayam & 123 & 117 & 110 & 2.750 & Gram \\
\hline Tepung & 33 & 30 & 25 & 1.550 & Gram \\
\hline Saus & 0 & 77 & 0 & 350 & Gram \\
\hline Cabai & 20 & 0 & 0 & 125 & Gram \\
\hline Bawang putih & 10 & 7 & 5 & 225 & Gram \\
\hline Minyak & 523 & 517 & 450 & 27.500 & Gram \\
\hline Waktu Pembuatan & 30 & 25 & 20 & 720 & Menit \\
\hline Harga & 16.000 & 13.000 & 14.000 & & Rupiah \\
\hline
\end{tabular}




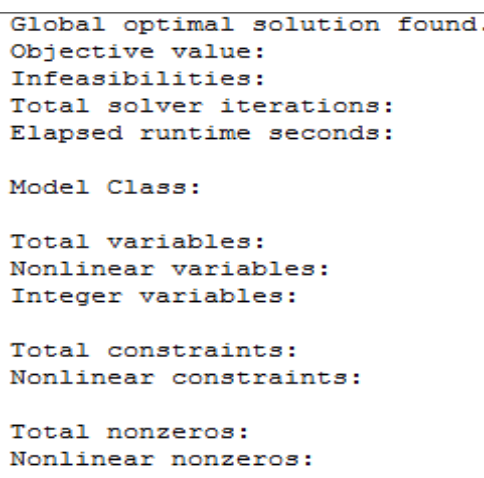

370859.5

0.000000

2
0.21

LP

Gambar 2 Hasil Metode Simpleks Menggunakan Aplikasi LINGO

\subsection{Hasil Perhitungan Metode Hungarian atau Assignment}

Pengolahan data menggunakan Hungarian (assignment) untuk pengoptimalan pembagian jam kerja dan tepat pada posisi tugas masing-masing, dengan hasil pengumpulan data waktu kerja setiap pegawai. Pengolahan data dilakukan dengan konsep perhitungan Hungarian secara manual dan perhitungan menggunakan software LINGO.

Pada perhitungan manual dengan cara mengikuti tahapan-tahapan perhitungan Hungarian dan mendapatkan Optimalisasi waktu kerja karyawan di oulet Lazatto Cabang UNSIKA di Karawang yaitu 83 menit atau 1 jam 23 menit/satu kali penggorengan atau produksi seperti pada Tabel 2.

Tabel 2 Waktu Kerja Pegawai Lazatto

\begin{tabular}{lccc}
\hline & Sri Nur Hayani & Devi Kurnia & Rian \\
\hline Ayam Geprek & 30 & 33 & 28 \\
Ayam Sadas & 25 & 27 & 24 \\
Ayam Goreng & 20 & 23 & 25 \\
\hline
\end{tabular}


Kemudian perhitungan dilakukan dengan menggunakan software LINGO dan didapatkan hasil sebagai berikut :

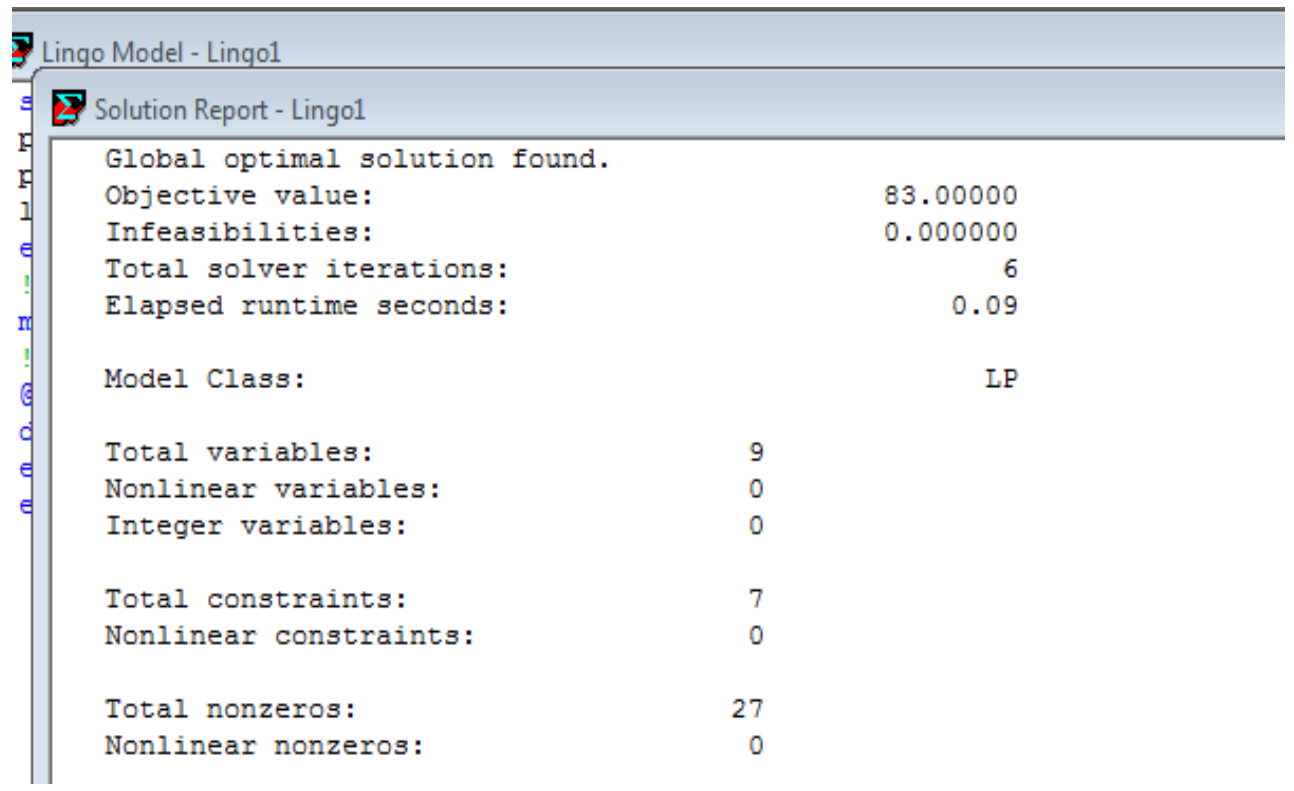

Gambar 3 Perhitungan Hungarian Menggunakan Software LINGO

Gambar 3 menjelaskan hasil perhitungan Hungarian dengan software LINGO yang juga mendapatkan waktu 83 menit atau 1 jam 23 menit/satu kali penggorengan, dilihat dari nilai Objective Value, hasil perhitungan manual dengan perhitungan menggunakan software LINGO mendapatkan hasil yang sama yaitu 83 menit. Sehingga dapat digambarkan alokasi penugasan seperti pada Gambar 4.

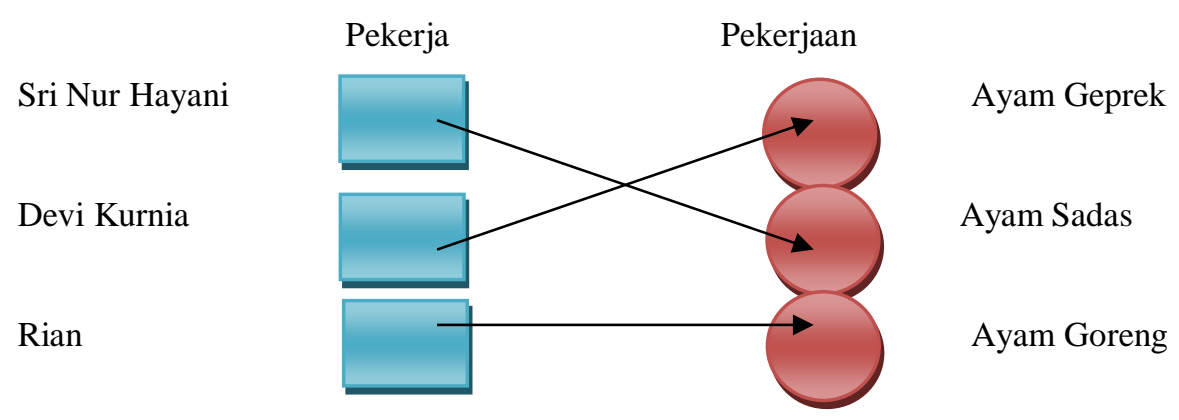

Gambar 4 Alokasi Penugasan Karyawan Lazatto

\subsection{Hasil Perhitungan Metode Minimum Spanning Tree}

Pengolahan data dalam rangka menemukan rute terdekat untuk mendistribusikan bahan baku kesetiap cabang Lazatto pada Gambar 5 terdapat jalur distribusi bahan baku Lazatto, notasi pada setiap cabang Lazatto dapat dilihat pada Tabel 3 dan perhitungan jarak pendistribusian bahan baku Lazatto sebelum menggunakan metode minimum spanning tree dapat dilihat pada Gambar 6. Perhitungan pada metode Minimum Spanning Tree akan diolah dengan dua cara yaitu perhitungan manual dan perhitungan menggunakan software QM fow Windows. 


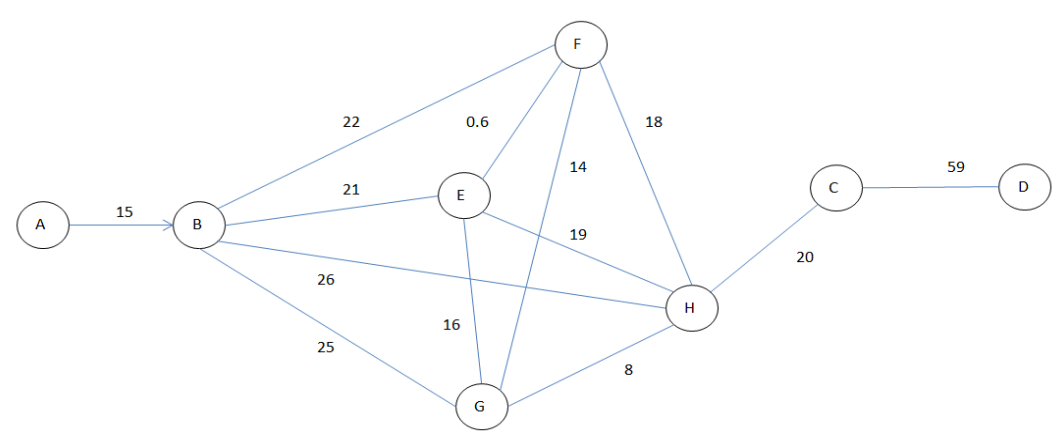

Gambar 5 Jalur Distribusi Bahan Baku Lazzato

Tabel 3 Keterangan Notasi Pada Cabang Lazatto

\begin{tabular}{cl}
\hline Kode & Cabang \\
\hline A & Purwakarta \\
B & Cikampek \\
C & Pinayungan \\
D & Telagasari \\
E & UNSIKA \\
F & UBP \\
G & Wadas \\
H & Perumnas \\
\hline
\end{tabular}

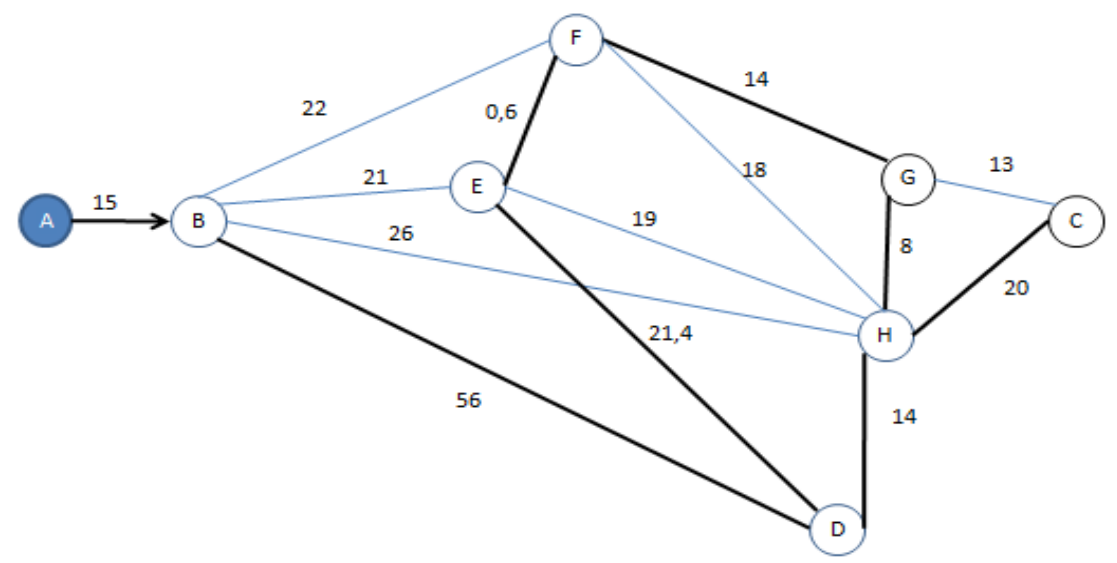

Gambar 6 Jalur Distribusi sebelum Menggunakan Metode Minimum Spanning Tree

Setelah mendapatkan jalur distribusi langkah selanjutnya memilih jarak terpendek yang menghubungkan setiap node dari sumber awal sampai tujuan akhir sebagai berikut:

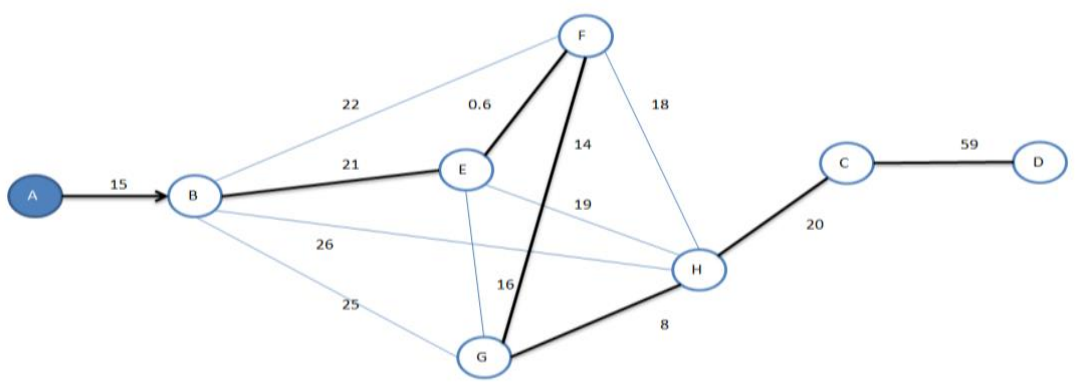

Gambar 7 Hasil Perhitungan Manual Minimum Spanning Tree 
Berdasarkan Graf minimum spanning tree mendapatkan hasil rute terdekat untuk pendistribusian bahan baku Lazatto dengan rute Purwakarta-Cikampek-Universitas Singaperbangsa KarawangUniversitas Buana Perjuangan-Wadas-Perumnas-Pinayungan-Telagasari dengan jarak 137,6 km dan waktu 2 jam 30 menit

Kemudian perhitungan dilakukan dengan Software QM for Windows dan mendapatkan hasl sebagai berikut :

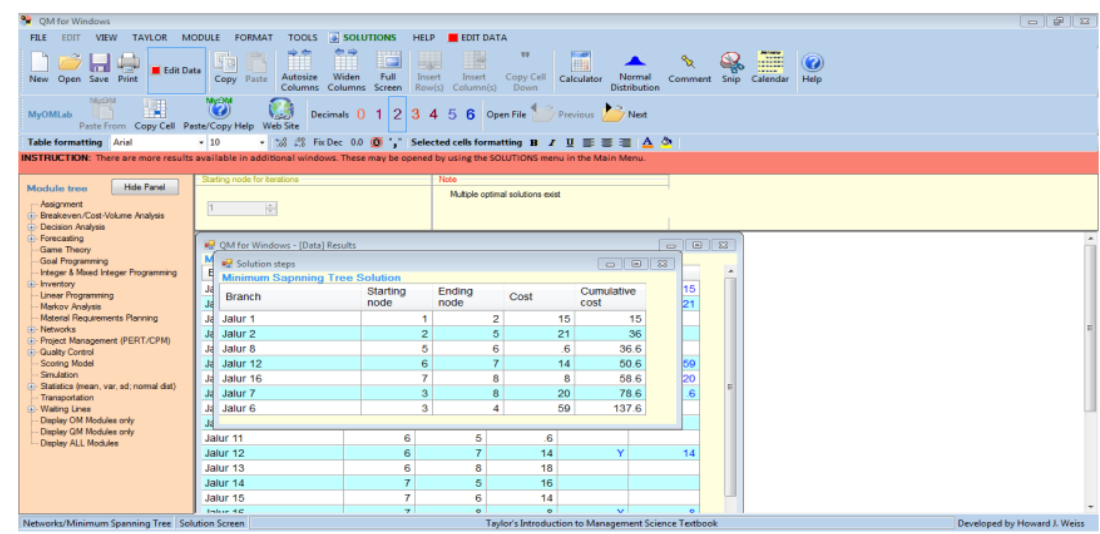

Gambar 8 Hasil Perhitungan Minimum Spanning Tree menggunakan Software QM for

Windows

Berdasarkan gambar diatas dapat dilihat hasil perhitungan menggunakan software QM for Windows dengan jarak optimum yaitu $137,6 \mathrm{~km}$.

\subsection{Pembahasan}

Berdasarkan hasil metode simpleks dengan Branch and Bound menggunakan software LINGO pada Gambar 2 maka Lazzatto untuk mendapatkan keuntungan yang optimal dalam satu kali produksi atau penggorengan maka jumlah produksi dalam satu kali slot produksi penggorengan berjumlah 23 potong ayam yang terdiri dari ayam geprek yang diproduksi 5 pcs (X1), ayam sadas 4 pcs (X2) dan ayam goreng 14 pcs (X3) dengan keuntungan maksimal Rp.370.000,-/produksi.

Sedangkan berdasarkan metode Hungarian atau assignment pada Tabel 2, Optimalisasi waktu kerja pada oulet Lazatto Cabang UNSIKA di Karawang mendapatkan hasil 83 menit atau 1 jam 23 menit/satu kali produksi dengan kombinasi ayam sadas selama 25 menit, ayam geprek 33 menit, dan ayam goreng 25 menit. Pada Gambar 3 menjelaskan hasil perhitungan Hungarian atau assignment menggunakan software $\mathrm{QM}$ for Windows dan mendapatkan hasil yang sama dengan perhitungan manual yaitu mendapatkan waktu 83 menit atau 1 jam 23 menit/satu kali produksi atau penggorengan, jika dibandingkan dengan waktu sebelumnya yaitu selama 1 jam 30 menit/satu kali produksi. Metode Hungarian lebih baik jika dibanding dengan metode di oulet Lazatto, dengan selisih waktu sebesar 7 menit.

Sedangkan untuk Optimalisasi Analisa distribusi pasok pada outlet Lazatto Cabang UNSIKA di Karawang setelah dilakukan perhitungan dengan menggunakan Minimum Spanning Tree pada 
Gambar 6 dihasilkan rute Purwakarta-Cikampek-Universitas Singaperbangsa KarawangUniversitas Buana Perjuangan-Wadas-Perumnas-Pinayungan-Telagasari dengan jarak 137,6 km dan waktu 2 jam 30 menit. Dari perhitungan menggunakan software QM for Windows pada Gambar 7 mendapatkan hasil yang sama dengan perhitungan manual yaitu 137,6 km. Jika dibandingkan jarak tempuh sebelumnya pada Gambar 5 yaitu 149 km dengan rute purwakartacikampek-telagasari-Universitas Singaperbangsa Karawang-Universitas Buana PerjuanganWadas-Perumnas-Pinayungan dengan waktu temput 2 jam 48 menit. Metode Minimum Spanning Tree dapat meminimasi jarak tempuh dengan selisih jarak 11,4 km dan selisih waktu tempuh yaitu 18 menit.

\section{Kesimpulan}

Optimalisasi waktu kerja pada oulet Lazatto Cabang UNSIKA di Karawang dengan menggunakan Hungarian atau assignment mendapatkan hasil 83 menit atau 1 jam 23 menit/satu kali produksi dengan kombinasi ayam sadas selama 25 menit, ayam geprek 33 menit, dan ayam goreng 25 menit.

Sedangkan untuk Optimalisasi Jumlah produksi pada outlet Lazatto Cabang UNSIKA di Karawang dalam satu kali produksi yang dihasilkan dari metode Branch and Bound yaitu sebanyak 23 potong ayam, dengan kombinasi ayam geprek sebanyak 5 potong, ayam sadas sebanyak 4 potong, dan ayam goreng 14 potong, serta hasil penjual optimal dalam satu kali produksi adalah sebesar Rp. 370.000 .

Sedangkan untuk Optimalisasi Analisa distribusi pasok pada outlet Lazatto Cabang UNSIKA di Karawang setelah dilakukan perhitungan dengan menggunakan Minimum Spanning Tree dihasilkan rute Purwakarta-Cikampek-Universitas Singaperbangsa Karawang-Universitas Buana Perjuangan-Wadas-Perumnas-Pinayungan-Telagasari dengan jarak 137,6 km dan waktu 2 jam 30 menit.

Keterbatasan pada penelitian ini hanya dilakukan pada salah satu oulet restoran cepat saji yaitu Lazatto, dan mungkin tidak dapat digeneralisasikan ke oulet lain karena datanya berbeda. Oleh Karena itu, untuk penelitian selanjutnya dapat dilakukan di oulet restoran cepat saji lainnya, dan pada setiap metode yang digunakan untuk memecahkan permasalahan diatas diharapkan penelitian selanjutnya dapat menggunakan metode yang berbeda untuk menganalisis metode yang paling optimum untuk memecahkan permasalahan penugasan, penjadwalan maupun analisa distribusi.

\section{Ucapan Terimakasih}

Ucapan terimakasih disampaikan kepada Lazatto atas diizinkannya untuk melakukan penelitian ini 


\section{DAFTAR PUSTAKA}

[1] V. Mandasari and B. Tama, "Analisis Kepuasan Konsumen Terhadap Restoran Cepat Saji Melalui Pendekatan Data Mining: Studi Kasus XYZ,” J. Generic, vol. 6, no. 1, pp. 25-28, 2011.

[2] "Tren Data Pertumbuhan Industri Makanan dan Minuman, 2010 - 2020," Data Industri, 2020. https://www.dataindustri.com/produk/data-pertumbuhan-industri-makanan-danminuman/.

[3] Ristono dkk, Ekonomi Teknik, Edisi Pert. Yogyakarta: Graha Ilmu, 2011.

[4] S. Bariasti and A. Lestari, "Penyelesaian Masalah Penugasan Menggunakan Metode Hungarian dan Pinalti," Sains Mat. dan Stat., vol. 3, no. 1, p. 1, 2017.

[5] E. Rahmawati, N. Satyahadewi, and F. Frans, "OPTIMALISASI MASALAH PENUGASAN MENGGUNAKAN METODE HUNGARIAN ( Studi kasus pada PT Pos Indonesia ( Persero ) Pontianak ),” vol. 04, no. 3, pp. 363-370, 2015.

[6] U. Tarigan and M. F. Ardiansyah, "Penerapan Fuzzy Min-Max Mamdani Untuk Memprediksi Jumlah Produksi Di Pt.Xyz," J. Sist. Tek. Ind., vol. 21, no. 2, pp. 43-51, 2019, doi: 10.32734/jsti.v21i2.1226.

[7] I. Masudin, D. M. Utama, and F. Susastro, "Penjadwalan Flowshop Menggunakan Algoritma Nawaz Enscore Ham," J. Ilm. Tek. Ind., vol. 13, no. 1, pp. 54-59, 2014.

[8] M. Firdaus, I. Masudin, and D. M. Utama, "Penjadwalan Flowshop Dengan Menggunakan Simulated Annealing," Spektrum Ind., vol. 13, no. 1, p. 27, 2015, doi: 10.12928/si.v13i1.1836.

[9] K. R. Baker and D. Trietsch, Principles of sequencing and scheduling. 2013.

[10] N. I. Lesmana, "Penjadwalan Produksi Untuk Meminimalkan Waktu Produksi Dengan Menggunakan Metode Branch And Bound," J. Tek. Ind., vol. 17, no. 1, p. 42, 2017, doi: 10.22219/jtiumm.vol17.no1.42-50.

[11] A. Akram, A. Sahari, and A. I. Jaya, "OPTIMALISASI PRODUKSI ROTI DENGAN MENGGUNAKAN METODE BRANCH AND BOUND (Studi Kasus Pada Pabrik Roti Syariah Bakery, Jl. Maleo, Lrg.VIII No. 68 Palu)," J. Ilm. Mat. Dan Terap., vol. 13, no. 2, pp. 98-107, 2016, doi: 10.22487/2540766x.2016.v13.i2.7209.

[12] A. Rahmawati and Mulyono, "Minimum Spanning Tree Pada Jaringan Pendistribusian," UNNES J. Math., vol. 4, no. 2, 2015.

[13] G. J. Hillier, F.S., \& Lieberman, Introduction to Operations Research (10TH ed.). New York: McGraw-Hill Education, 2012.

[14] E. R Gultom, "Merefungsi Pengangkutan Laut Indonesia Melalui Tol Laut Untuk Pembangunan Ekonomi Indonesia Timur," Develop, vol. 1, no. 2, 2017, doi: 10.25139/dev.v1i2.381.

[15] H. Sarjono, "Determination of best route to minimize transportation costs using nearest neighbor procedure," Appl. Math. Sci., vol. 8, no. 61-64, pp. 3063-3074, 2014, doi: 10.12988/ams.2014.43225.

[16] D. A. R. Wulandari and F. N. Arifin, "Penentuan Rute Terpendek Jalur Distribusi Air Artesis Menggunakan Kruskal," J-SAKTI (Jurnal Sains Komput. dan Inform., vol. 2, no. 2, p. 121, 2018, doi: 10.30645/j-sakti.v2i2.72.

[17] H. Li, W. Mao, A. Zhang, and C. Li, "An improved distribution network reconfiguration method based on minimum spanning tree algorithm and heuristic rules," Int. J. Electr. Power Energy Syst., vol. 82, pp. 466-473, 2016, doi: 10.1016/j.ijepes.2016.04.017.

[18] S. Rizki, "Penerapan Teori Graf Untuk Menyelesaikan Masalah Minimum Spanning Tree (Mst) Menggunakan Algoritma Kruskal," AKSIOMA J. Math. Educ., vol. 1, no. 2, 2012, doi: 10.24127/ajpm.v1i2.68.

[19] Sugiyono, Metode Penelitian Kuantitatif Kualitatif dan R\&D. Bandung: Alfabeta, 2012.

[20] \& L. Hilier, Frederich S., Introduction to Operation Research, Schaum Ser. McGraw-Hill, 1990.

[21] M. Saiful, A. Rapi, and W. Flannery, "Penjadwalan Produksi Dengan Metode Branch and Bound Pada Pt. Xyz," Bksti, pp. 2-6, 2014.

[22] W. Nur and N. M. Abdal, "Penggunaan Metode Branch and Bound dan Gomory Cut dalam Menentukan Solusi Integer Linear Programming,” Saintifik, vol. 2, no. 1, pp. 9-15, 2017, doi: 10.31605/saintifik.v2i1.91.

[23] M. Paendong and J. D. Prang, "Optimisasi Pembagian Tugas Karyawan Menggunakan 
Metode Hungarian,” J. Ilm. Sains, vol. 11, no. 1, p. 109, 2011, doi: 10.35799/jis.11.1.2011.52.

[24] Nelfiyanti \& Dermawan. D, "Penentuan Rute Distribusi Bbm Yang Optimal Menggunakan Metode Minimal Spanning Tree Dan Alogitma Heuristik Di PT. Telkomsel Area Kabupaten Pelalawan,” J. Tek. Ind. - Univ. Bung Hatta, vol. 1 No.1, pp. 58-69, 2012. 